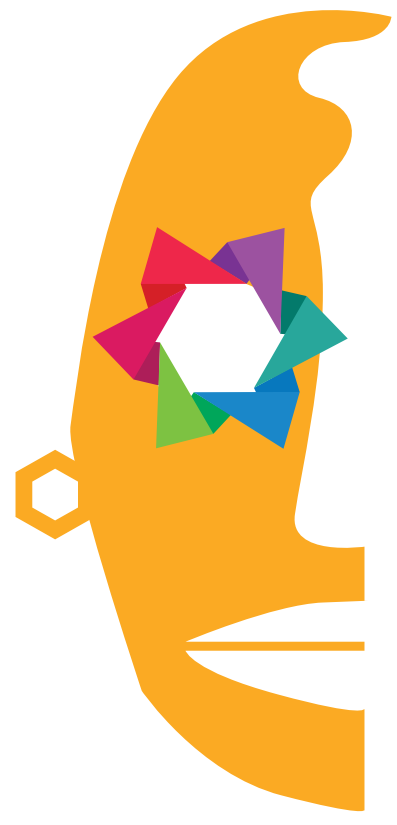

\title{
Contrapuntos de la
} "heroica" a la "fantástica": institucionalización de la música nacional, prácticas de resistencia "negras" "populares" e interculturalidad en Cartagena de Indias

\section{Counterpoints from the} "heroic" to the "fantastic":

Marcelo José

\section{Cabarcas Ortega}

University of Pittsburgh

Estados Unidos institutionalization of national music, "black" "popular" resistance practices and interculturality in Cartagena de Indias

\section{RESUMEN}

Este trabajo entiende lo musical como dinámica cultural híbrida y como espacio de resistencia simbólica y material, corporal y subjetiva, que se manifiesta entre formas culturales hegemónicas y subalternizadas. Se parte de la idea de hibridez para analizar la capacidad de adaptación y resistencia de los movimientos culturales y, por esa vía, reflexionar sobre el universo social del Caribe colombiano. Tres aspectos se estudian con este fin: primero, los procesos de institucionalización de la música nacional y su impacto en la conformación de la música popular; segundo, las relaciones entre la cultura oficial y las prácticas negras "populares"; y tercero, la interacción entre lo hegemónico y lo subordinado como medio de reconfiguración de los 
ritmos y estilos cotidianos. Este texto parte de una perspectiva ensayística e interdisciplinar, propia de los estudios culturales, para contribuir a los debates sobre cultura, marginación y resistencia en el Caribe colombiano, en particular, e hispánico, en general.

Palabras Clave: resistencia cultural, hibridez, contrapunteo, música y cultura popular, Caribe colombiano

\begin{abstract}
This paper depicts popular music as both hybrid dynamics and space of symbolic and material resistance, that is, as an interplay between canonic and subalternized cultural forms. It departs from the idea of hybridity to analyze the adaptability and resistance of cultural movements and, in such way, reflect on the past and present of specific Colombian Caribbean's societal settings. Three aspects are addressed here to this end: first, the institutionalization of high-end national music and its impact on shaping the vernacular; second, the relationship between the official culture and the "popular", black, vernacular practices; and third, the interactions between the hegemonic and the subordinate as a means of reconfiguring daily life's rhythms and styles. The standpoint of this text is essay-like and interdisciplinary, pertaining to cultural studies, and its aim is to contribute to the current debates on culture, marginalization and resistance in the Colombian Caribbean, in particular, and the Hispanic Caribbean, in general.
\end{abstract}

Keywords: cultural resistance, hybridity, counterpoint, vernacular music and culture, Colombian Caribbean

Se sabe bien que las diferencias de clase, etnia o posicionamiento son centrales en la construcción de los cánones estéticos, se sabe también que estas diferencias tienen un rol en la producción y consumo de la cultura y los bienes culturales. Sin embargo, existe cierta porosidad, cierta comunicación, entre las formas en que estas distintas clases, colectivos o comunidades piensan y crean culturalmente, es decir, entre sus variados objetos, prácticas y manifestaciones. Así pues, la aparente brecha entre lo civilizado, bello y deseable, y aquello que se le opone, no es tan grande si se le piensa dentro de un marco dialógico, que comprenda los procesos de amalgamiento por los que han atravesado todos los grupos dentro de las sociedades contemporáneas. Por un lado, no se pueden obviar desigualdades que son evidentes: de acuerdo con Stuart Hall, los grados diferenciales de acceso al mundo de la producción y el consumo, que funcionan como marcadores de distinción, son la base de las ideas imperantes sobre la alta y baja cultura. Sin duda, esta dualidad ha sido fundamental como mecanismo histórico "de construcción de sentido" y de ordenamiento material, pues dentro de una modernidad racial, sexual y económicamente fragmentada, las distancias entre lo alto y lo bajo se traducen, en la gran mayoría de los casos, en las brechas que existen entre escasas y desproporcionadamente altas tasas de representatividad y participación política ${ }^{1}$.

1 Stuart Hall, <<Estudios Culturales: dos paradigmas $>>$, en Sin garantias. Trayectorias y problemáticas en Estudios Culturales, comp. Eduardo Restrepo, Catherine Walsh y Víctor Vich (Ecuador: Corporación Editora Nacional/Universidad Andina Simón Bolívar, 2013), 29-51. 
Por otro lado, sin importar cuan fuerte sea el afán de categorizar y dividir, los contenidos de lo que es alto y de lo que es bajo resultan siempre fluctuantes, pues las nociones de lo culto e inculto "cambian de un momento histórico a otro"2. Al no mantenerse fijas, estas imposibilitan la labor de quienes detentan poder e intentan determinar rutas fijas para los procesos culturales. Esta distancia entre lo que las élites consideran deseable, y la realidad de la cultura popular, genera imposiciones al igual que resistencias. Mientras desde arriba se puja por un ideal estético (y por ello social) clasista; los de abajo, la vida subalterna, "se resiste a ser constantemente tratada como despreciable y extraña". Cartografiar el impacto que estas dinámicas de coacción y resistencia tienen sobre la vida social, económica y política de las comunidades resulta bastante fructífero, puesto que ofrece "un tipo especial de mapa a través del cual puede explorarse la naturaleza de los cambios" que las mismas atraviesan ${ }^{3}$.

Partiendo de lo anterior, este trabajo entiende el escenario musical cartagenero como un campo de batalla cultural que funciona de tres maneras específicas. Primero, como espacio/tiempo híbrido que combina lo subordinado y lo hegemónico para poder seguir creando e innovando. Segundo, como un espacio/tiempo que las clases subordinadas instrumentalizan en su lucha por una mayor inclusión simbólica. Tercero, como matriz cultural que se proyecta en la subjetividad y la corporalidad de los individuos. Durante su desarrollo, la idea de hibridación actúa como eje articulatorio de estas intersecciones.

Bhabba aduce que la hibridez es un terreno de luchas en la medida que posibilita que una forma cultural dominante interactúe con las practicas que le son subordinadas ${ }^{4}$. Sin embargo, aunque surja de unas jerarquías de poder, esta interrelación está lejos de constituir un vínculo predeterminado y univoco, pues la hibridez no es tanto la asimilación dócil de la dominación como las formas en que el dominado resiste apropiándose de modos ajenos de sentir y ver el mundo. En el caso de las prácticas culturales surgidas en las periferias del mundo social, esta resistencia se expresa, entre otras cosas, en la ambigüedad con que dichas prácticas negocian con una tradición universal que provee matrices y modelos pero que subvalora, al mismo tiempo, la especificidad de su propio lugar enunciativo.

Mediante esta negociación con jerarquías y ordenes de sentido en apariencia superiores, las dinámicas y prácticas socialmente denigradas construyen un tercer espacio en el cual, al decir de Bhabba, lo dominado ejecuta procesos específicos

2 Hall, $<<$ Estudios Culturales... $>>, 29$.

3 Stuart Hall, $<<_{i}$ Qué es lo "negro" en la cultura popular negra? >>, en Sin garantías. Trayectorias y problemáticas en Estudios Culturales, comp. Eduardo Restrepo, Catherine Walsh y Víctor Vich (Ecuador: Corporación Editora Nacional/Universidad Andina Simón Bolívar, 2013), 297.

4 Homi Bhabba, El lugar de la cultura (Argentina: Estudio R cultura libre, 1994). 
de iteración y traducción de lo dominante. A través de estas dos operaciones, lo subordinado negocia con la otredad que se le contrapone, lo cual significa que, a pesar de las relaciones desiguales en las cuales se enmarca su producción, lo popular acepta que el encuentro con la diferencia, representada por la matriz de lo hegemónico, es inevitable. Lo que se produce a partir de este encuentro, que no es un resultado abstracto, sino que se palpa en la materialidad de los modos de sentir y hacer con el cuerpo es, a su vez, un entrecruzamiento de la cultura popular y la propia de las élites, de lo incluido y lo excluido, de lo simbólico y lo material.

Michael Veal aterriza lo anterior en el terreno concreto de los estudios sonoros cuando concibe la hibridez musical caribeña como una urdimbre de discursos, prácticas, saberes y sensibilidades que se corporeizan y hacen subjetividad a través de movimientos simultáneos de reinvención y mimesis ${ }^{5}$. Dentro de este lenguaje, la remezcla lingüístico-genérica, la reverberación y la fragmentación de la superficie sonora se constituyen en metáforas de la ineludible multiplicidad psico-social de los sujetos. Aunada a lo anterior aparece, entonces, la idea de la metáfora social como símbolo que proyecta un imaginario que es, a la vez, cultural e individual, y que demuestra el poder figurativo de los movimientos culturales.

Visto a la luz de estas metáforas sociales, el "ritmo" popular no solamente existe como tejido acústico, es también componente de todas las gamas de lo experiencial. Se transforma, en ese sentido, en una cadencia que expresa la vida en su totalidad. De lo anterior se desprende, por supuesto, una reivindicación de tipo político. El ritmo se transforma, en su significado más profundo, en una manera de resistir y expresarse libremente, de oponerse a la opresión material y simbólica del cuerpo, una opresión que proviene, a su vez, de las formas en que el individuo es entendido por los regímenes intelectuales de la modernidad.

Estas oscilaciones permiten plantear la noción de contrapunto, un término musical, como metáfora para pensar el mundo cultural cartagenero. Pensar en términos de contrapunto resulta útil no solo por su pertenencia al campo semántico propio de la temática abordada, sino porque permite asumir la contrariedad y la ambivalencia de dicha realidad, pues implica pensar en la coexistencia de líneas musicales que, como los movimientos que a continuación se describen, siguen conservando un vínculo estable a pesar de que parecen desarrollarse de formas separadas.

Con el fin de abordar dichos movimientos, este trabajo se divide en tres partes. La primera parte consiste en un análisis de los procesos de institucionalización de la música nacional en Colombia y su impacto en la conformación de una idea de música popular cartagenera que se nutre del ideal ilustrado republicano. La segunda parte trata de establecer las relaciones entre dicha música, pensada como la

5 Michael Veal, <<Starship Africa $>>$, en The Sound Studies Reader, ed. Jonathan Stern (Londres: Routledge, 2012). 
auténtica expresión de la cultura popular oficial "hispánica”, y las prácticas culturales consideradas como "negras" "populares" y, como tal, difícilmente asimilables. Se evidencia que, lejos de constituirse en matrices divergentes, ambas formas culturales están en una relación conflictiva de rechazo y mimesis mutua. La tercera y última parte consiste en ver como las prácticas surgidas de esta interacción entre lo hegemónico y lo subordinado han creado una cultura cartagenera marcada por la pluralidad lingüística y genérica. Se explica, además, como esta pluralidad se palpa en los ritmos y estilos de vida de la gente que habita la ciudad cotidiana.

\title{
1. Primera voz del contrapunto: modernidad y sonoridad en la ciudad "heroica"
}

\subsection{Música, símbolo y ciudadanía}

La del himno de Cartagena es una historia interesante, que involucra la colaboración de dos de las figuras culturales más representativas del Caribe colombiano del siglo XX en la construcción de una de las tonadas más singulares de la cultura colombo-caribeña del siglo XX. Tocado en tempo di marcia, acompañado de instrumentación clásica para el canto, se puede escuchar su partitura sonora dentro de un acompañamiento sinfónico completo, marcado por la vibración intensa de los metales y el ritmo de ópera italiana que envuelve sus estrofas, dándole a la interpretación ese tono épico que distingue a los himnos republicanos:

\author{
Suenen trompas en honor \\ De la noble e inclita ciudad \\ Que por patria se inmoló \\ Con sus gestas gloriosas de libertad \\ Coro \\ Libertad, libertad, la fe con ardor grito \\ $Y$ en un once de noviembre \\ Fue la heroica Cartagena \\ Quien del yugo las cadenas \\ Cual Leona fiera destrozó ${ }^{6}$
}

Curiosamente, en los '50, cuando el compositor Adolfo Mejía y el intelectual Eduardo Lemaitre decidieron erigir un canto a la gloria republicana de Cartagena, ambos estaban recorriendo, a sabiendas, un camino antes recorrido, una repetición centenaria que remite a los principios de la empresa nacional. Que esta empresa guarde, en lo cultural, muchas ambigüedades, es cosa bien sabida, que sea Carpentier quien desde otra orilla abra el camino para entenderlas, resulta

6 "Himno de Cartagena de Indias," Youtube, subido por Jhoyner Licona, febrero 7, 2011, https://www.youtube.com/watch?v=wLhxJVn9AM4 
llamativo. En opinión del cubano, el asunto tiene que ver con la formación de los campos musicales de las jóvenes republicas del siglo XIX:

(...) la adquisición de la nacionalidad se acompañó de una momentánea subestimación de los valores nacionales. El país nuevo aspiraba a recibir las grandes corrientes de la cultura, poniéndose al día. Por un lógico proceso evolutivo, toda independencia lograda viene unida al deseo de aplicar nuevos métodos, de estar up to date, de barrer con todo lo que pueda parecer un lastre de provincialismo o de coloniaje (...) Por ello, en todas las naciones se llevaron a cabo esfuerzos casi idénticos destinados a consolidar la vida musical, a institucionalizar la música y a situar su estudio y práctica en el centro mismo de las sociedades?

Lo anterior reafirma un rasgo harto conocido de la modernidad latinoamericana: para propiciarla, la idea es, desde el principio, abrir la nación a las grandes corrientes de la civilización, corrientes que, vistas en propiedad, constituyen los movimientos literarios, intelectuales y musicales de Europa. De acuerdo con Miranda y Tello, la política cultural del XIX implica, en todo el continente, un esfuerzo consciente para institucionalizar la música de cámara ${ }^{8}$. Por esa razón, las sociedades filarmónicas, academias y conservatorios se convierten en la herramienta para reconfigurar, mediante la alta cultura, la identidad de las nuevas democracias americanas. Se inauguran, a mediados del XIX, las instituciones musicales que, desde Buenos aires, Ciudad de México, Caracas y otras capitales, velaran por el mantenimiento de este ideal civilizatorio. En el caso de Santa fe de Bogotá, que no es ninguna excepción, se abre una academia de música en 1845. $\mathrm{Su}$ influencia en la conformación de una noción de música colombiana será decisiva a partir de entonces.

Es justamente en este contexto europeizante que los himnos nacionales van fraguándose poco a poco: Bolivia, Argentina, Ecuador, Costa Rica, Bolivia, México, Chile, Uruguay, Paraguay, Honduras, Panamá, El Salvador y Brasil evidencian, detrás de la motivación nacionalista de sus respectivos himnos, una profunda imitación del romanticismo y de la ópera italiana. El caso de Colombia no resulta para nada diferente.

Sin embargo, hay que especificar una particularidad propia del caso colombiano: lo que hoy se conoce como el himno nacional de la república no fue compuesto, en principio, como el himno nacional de la república. Escrito en 1887 por el aristócrata cartagenero Rafael Núñez, quien por entonces fungía como presidente de la nación, la letra constituye, en principio, un poema elegiaco a las gestas locales de independencia. Este poema algo dulzón, compuesto por once estrofas alejandrinas, a caballo entre lo neoclásico y lo romántico (es decir, pasado de moda

7 Alejo Carpentier, La música en Cuba (México: Siglo XXI editores, 1987), 429.

8 Ricardo Miranda, Aurelio Tello, La música en Latinoamérica (México: Secretaría de relaciones exteriores, 2011). 
para su época) es musicalizado por el compositor de opera italiano Oreste Sindici y presentado al público en la forma de canto a la patria, tal es, de canción épica sin carácter oficial. Deberá esperarse hasta 1920, época para la cual ya se había convertido en una tonada tremendamente popular, para que se le adopte como el himno protocolar de la nación". Este es el modo en que unos "versos alegres de tonada elegante", pensados como tributo a la "heroica Cartagena" y luego recitados en el marco de unos juegos florales, se transforman, eventualmente, en la sinfonía encargada de representar la idea misma de la "colombianidad".

Esta colombianidad es una identidad nacional concebida en tonalidad de Mi bemol mayor. Una musicalidad que hace eco de la univocidad ética y la universalidad racional del ser político que la escucha. Su público es el sujeto autónomo, ilustrado, defensor de la constitucionalidad y de sus derechos y deberes. La actitud solemne que este sujeto mantiene, la intercalación solemne y pausada de silencio y declamación, es un reflejo perfecto de su autogobierno, de esa capacidad para dirigir su propia vida que se proyecta sobre los asuntos del estado. La modernidad política del himno es, a la par, la mayoría de edad de quien la escucha.

Escrito casi 80 años después del periodo en que aparecen los primeros himnos nacionales, el himno de Cartagena se puede pensar como un intento de mostrar la conciencia moderna del ciudadano cartagenero y su lugar en la nación. Sin embargo, al pensar en lo anterior, una contradicción se hace evidente. Firmemente anclados en el ideal del símbolo patrio, Lemaitre y Mejía erigen un canto a una Cartagena a la altura de los tiempos que, a pesar de todo, está llena del espíritu ennoblecedor de la gesta civilizatoria española. La Cartagena colombiana es fiel continuadora, en ese sentido, de la Cartagena española. La grandeza de la república hace eco, mediante el arte y la pompa, de la grandeza de la colonia:

\section{Suenen trompas en honor \\ De la noble e ínclita ciudad \\ Que por patria se inmolo \\ Con sus gestas gloriosas de libertad}

Con todo, el himno no pasa de ser un tardío delirio de grandeza. Paradójicamente, Cartagena de Indias es, desde su independencia hasta mediados del siglo XX, una ciudad en decadencia. Es solamente entre 1914 y 1948 que arranca el rediseño que la convierte en un afamado centro turístico. La prerrogativa de las élites de ese momento es la reconstitución del entorno urbano de acuerdo a una idea que copia lo más posible del imaginario norteamericano de la Habana de las postales. Una ambición que acarrea un cambio morfológico profundo, que se va a centrar

9 "Himno nacional de la república de Colombia," Youtube, subido por Presidencia de la República de Colombia, augusto 7, 2014, https://www.youtube.com/watch?v=SrvKADxxsqg 
en tres ejes: la higienización, la instalación de servicios públicos y el embellecimiento de las zonas vitales para el turismo.

Este embellecimiento marca, no obstante, el principio de un modelo de ciudad en el cual la exclusión pasa a ser el rasgo social predominante. Por supuesto, las razones de esta exclusión son históricas. A medida que su rediseño tiene lugar, las profundas desigualdades sociales de la Cartagena colonial se van haciendo cada vez más evidentes, desigualdades que obligan a la dirigencia de "la heroica" a resolver problemas hasta ese momento ignorados: ¿cómo integrar a las enormes comunidades "premodernas" cartageneras en el nuevo esquema turístico de desarrollo? ¿cómo vender la ciudad sin que se note la presencia de la numerosa chusma que la afea? ¿cómo esconder la ciudad nativa que se extiende por todas partes como una gigantesca mancha de pobreza? ${ }^{10}$

\subsection{Amor por la piedra, desprecio por la gente: dilemas de la modernidad cartagenera}

Así se ha llegado a una organización de la ciudad a partir de esa imagen legitimada, que disciplina y da coherencia al espacio a través de una doble actuación: la redención y purificación del territorio, y la monumentalización de la ciudad por "la implantación de monumentos de fuerte arraigo simbólico" ${ }^{\prime 1}$

Estas preguntas siguen esperando una respuesta. La verdad es que Cartagena se embelleció y se vendió como la más Caribe de todas las ciudades del Caribe sin que se haya saldado su profunda deuda social. En su posicionamiento como

10 Para ampliar las discusiones en torno al desarrollo urbano de Colombia, Cartagena de Indias y el Caribe colombiano, ver Alberto Abello Vives, <<Introducción>>, en Los desterrados del paraíso. Raza, pobreza y cultura en Cartagena de Indias, ed. A. Avello Vives y F. Flórez Bolívar (Cartagena: Instituto de Cultura y Turismo de Bolívar / Icultur Gobernación de Bolívar, 2015), 6-9.

Orlando Dávila Pertuz, <<Construyendo sospechas: imaginarios del miedo, segregación urbana y exclusión social en Cartagena 1956-1971 >>, Cuadernos de Literatura 7, (2008) http://investigaciones.uniatlantico. edu.co/revistas/index.php/cuadernos_literatura/article/view/477

Instituto de Crédito Territorial, Chambacú: Regeneración de una zona de tugurios (Cartagena: ICT, 1956).

Instituto de Crédito Territorial, Zona Negra (Cartagena: ICT, 1955).

Claudia Mosquera Rosero-Labbé, Marion Provansal, $<<$ Construcción de identidad caribeña popular en Cartagena de Indias por medio de la música y el baile de champeta $>$, en Los desterrados del paraíso. Raza, pobreza y cultura en Cartagena de Indias, ed. A. Avello Vives y F. Flórez Bolívar (Cartagena: Instituto de Cultura y Turismo de Bolívar / Icultur /Gobernación de Bolívar, 2015), 422-49.

Niño, Soledad et al., Territorios del miedo: imaginarios de los ciudadanos (Bogotá: TM Editores - Observatorio de Cultura Urbana, 1998).

Osiris María Chajín Mendoza, << "Los poetas de sus asuntos": migraciones, rupturas y reconfiguraciones de las culturas juveniles en Cartagena $>>$, Cuadernos de Literatura 7, (2008). Acceso septiembre 19, 2021. http:// investigaciones.uniatlantico.edu.co/revistas/index.php/cuadernos_literatura/article/view/489.

11 Delgado Ruiz como es citado por Mónica Lacarrieu, $<<$ La insoportable levedad, de lo urbano $>>$, Eure-revista Latinoamericana De Estudios Urbano Regionales - EURE 33 (2007): 54. 
Contrapuntos de la "heroica" a la "fantástica": institucionalización de la música nacional, prácticas de resistencia "negras" "populares" e interculturalidad en Cartagena de Indias

centro turístico, entra a operar una lógica contradictoria que la ciudad ha sido incapaz de superar, pues:

(...) las jerarquizaciones sociales que subrayaban las diferencias entre sectores populares y sectores de élite heredadas del esclavismo y la estigmatización sociocultural sobre los indígenas (...) llevaron a planear una ciudad con mayor atención a los espacios privados y que contrastaban con el otro lado de la ciudad pobre, periférica, que creció en dimensión física, mas no en progreso ${ }^{12}$.

Con esta segregación de las áreas pobres en aras del interés comercial, Cartagena se empieza a reconfigurar como una ciudad monumento, como una vitrina vacía de dinámicas sociales realmente integradoras entre sus diversos sectores constitutivos. A medida que el progreso se concentra cada vez más en las partes de la ciudad que contienen el patrimonio histórico, "el corralito" sufre una profunda transformación, pues pasa a ser, gradualmente, una ciudad des-corporeizada, en la que, mientras lo material pierde peso específico, el sentido de lo simbólico toma cada vez mayor cuerpo ${ }^{13}$. La consecuencia de este ensanchamiento simbólico de los hitos históricos es una profunda discriminación: al borrar a los sujetos populares del flujo y reflujo de imágenes e imaginarios mediante los cuales se construyen las representaciones sociales, se deja de lado, inevitablemente, la centralidad de la cultura popular en la edificación de la "cartageneidad". Esto explica porque en el discurso oficial de Cartagena la construcción de imágenes e imaginarios urbanos muestra más interés en las edificaciones, los baluartes y los monumentos que en las vivencias y prácticas de los ciudadanos de carne y hueso.

Nace entonces el destino turístico en el que conviven, paralelos, el culto al ladrillo y el desprecio a la gente. Símbolos contrapuestos, el glorioso pasado hispánico del monumento estará contrapuesto, en lo discursivo, a una realidad etnocultural "indeseable", radicalmente diferente a la noción de "buen ciudadano" a la europea defendido por las élites locales y nacionales ${ }^{14}$.

Este es el contexto en que se compone el himno de Cartagena. Surgido de la necesidad de darle a la ciudad un sentido de identidad musical acorde con su súbita re-afiliación hispánica, guarda, a todas luces, un sentido de lo monumental que lo convierte en un símbolo más de la urbe que acaba de ser inventada para el visitante, una Cartagena donde cualquier vestigio de la cultura del pueblo ha sido barrido por debajo de la alfombra para complacer el sentido de buen gusto de las

12 Isela Caro, $<<$ Cartagena: ciudad monumental para el turismo y discurso glorificador en la prensa local de mediados del siglo XX>>, Visitas al patio 5 (2011): 72.

13 Caro, "Cartagena: ciudad monumental...", 67-84.

14 Dávila Pertuz, "construyendo sospechas: imaginarios del miedo, segregación urbana y exclusión social en Cartagena 1956-1971". Para ver discusiones en torno al urbanismo en Latinoamérica a principios de siglo XX ver Shawn William Miller, An Environmental History of Latin America (Cambridge: Cambridge University Press, 2007). 
élites. Uno puede imaginarse a Lemaitre y Mejía contemplando con satisfacción la ciudad que se transforma rápidamente ante sus ojos. Embelesados, apoltronados lo más burguesamente posible en sus balcones coloniales, se dedican a mirar como las callejas de los pobres desparecen para dar paso a las avenidas y los bulevares por donde transitaran, igual de cetrinos y rubios, los cartageneros decentes y los turistas. Al fondo, como celebrando esta metamorfosis, el intenso brillo del sol se derrama sobre el espejo plateado de un mar que parece saludarlos. No es de sorprender que esta postal, que no es más que una cursilería, constituya una imagen potencialmente inspiradora para el himno.

Por lo pronto, ambos trabajan juntos para alcanzar una meta clara: la Cartagena que empieza a perfilarse en los ' 50 merece, como las naciones que se levantan, un canto que exprese su gloria. Para entonar este canto, de pie, tieso y solemne, con una mano en el corazón y la otra empuñando la bandera, está ese sujeto universal ilustrado tan anhelado por la república. Resulta concebible la satisfacción de Mejía y Lemaitre al imaginarse a este ciudadano formado para el acto cívico, concebible también su dicha al pensar lo exitosa que ha sido esta nueva Cartagena en la disimulación de su lado más primitivo. Satisfechos, se puede pensar en ellos fantaseando sobre lo siguiente que, en todas las dependencias y escuelas de la ciudad, personas blancas, rubicundas por el sol, están celebrando con su obra la efeméride de turno. En cada uno de esos lugares, el estertor de los metales resuena junto al estribillo que los ciudadanos recién empiezan a memorizar. Mientras todo esto sucede, el resplandor cae inclemente sobre la ciudad, sobre las calles y las plazas con nombres de antiguos marqueses, sobre la estatua de mármol recién erigida a Cristóbal Colon, santo civilizador de las Américas.

\section{2. "Nota contra nota" del contrapunto: ritmos y sentidos convergentes}

¿Habrá alguna forma de construir un puente entre la Cartagena que las élites se inventaron para incentivar el turismo y la ciudad auténtica que habitan los cartageneros? Para comenzar, la Cartagena turística, en su proceso de construcción, empieza a dar mayor importancia a la producción y apropiación hedonista de los cuerpos, la cultura y el espacio público. Por eso se tornan vitales, dentro del imaginario turístico, los modos sensoriales de percibir la ciudad: el olor, la degustación, la observación y la posibilidad de tocar las cosas que están en la zona turística son, por una parte, la cara deseable de esta moneda, por otra, se encuentra lo prohibido: la ciudad, las experiencias y los cuerpos de desecho que sobran en la nueva Cartagena. La ciudad, como todo balneario, se esfuerza en ser y parecer una burbuja, un ámbito privilegiado del placer, donde prestantes turistas, vestidos de impecable lino, pasean por callejas centenarias bajo la luz tenue de la última tarde. En las aceras de los restaurantes, hermosas jóvenes de piel "café con leche" los reciben con un menú y una sonrisa amplia, brillante y exótica. 
Eso demuestra que Cartagena, como todo destino turístico del Caribe, tiene una ambivalencia ineludible; pues para seguir existiendo como industria del placer, necesita la otredad pobre, negra y mulata que produce para ella labor doméstica y cuerpos para el deseo. Eso produce una situación de liminalidad para la cultura popular. La urbe necesita de lo otro para tender camas y manteles y para darle vida a un ideal de sensualidad tropical, pero esta necesidad no lo incluye todo, pues solo requiere de la porción de esa otredad que resulta domesticable, la dosis de cultura local necesaria para mantener marchando los motores libidinales del turismo.

Esto desemboca en una bifurcación de lo popular. Una parte de la cultura cartagenera se transforma en una manifestación híbrida que toma la práctica y el saber autóctono y lo adapta a la expectativa que el visitante tiene sobre el Caribe. Esto implica mezclar lo popular con los imaginarios, los saberes y las prácticas "blancas" de las élites locales y los visitantes. Evidencias de esta operación abundan en los puntos álgidos de la transacción turística: un mulato con maracas, en una guayabera de hilo, toca su versión de un son cubano para los comensales de un restaurante exclusivo. Mientras oyen sin escuchar, estos comensales escogen de la carta un plato de patacones (tostones) preparados con alguna salsa gourmet asiática. Por fuera, visibles desde las ventanillas, los grupos de bailarines ejecutan, por unas monedas, bailes "autóctonos" que bien tienen rasgos de lo que los europeos esperarían ver en Martinica, Cuba o Trinidad.

Sin embargo, una posibilidad surge de todo esto. Esta Cartagena surgida del contacto, que es a la vez popular y elitista, oficial y subordinada, ha creado un horizonte de producción cultural rico en formas de autorreconocimiento. Paradójicamente, es esta parte de la cultura, que tiene la ventaja y el infortunio de verse a sí misma en los ojos del otro, la que más tiende a reconocerse en la sumisión que se le ha impuesto. Al no poder mentirse a sí misma, o deformarse en los mecanismos coloniales de auto-blanqueamiento, esta cultura tiende a interpretarse tal y como es, al menos desde su posicionamiento sociopolítico. Gracias a la violencia del contraste, las meseras y el músico dentro del restaurante, así como los bailarines de la calle, saben bien cuáles son las contradicciones e inequidades del cosmopolitismo que se cierra y se abre ante sus subjetividades populares.

Esta conciencia, creada en el tránsito que estos sujetos mantienen de una esfera de la ciudad a la otra. Los sujetos subordinados en Cartagena, lejos de ser autómatas turísticos sin conciencia, conocen y negocian bien con los poderes y las dinámicas que legitiman su subordinación. Esta agencia surge, curiosamente, de una apertura a lo otro. La mezcla de elementos europeos, caribeños y norteamericanos que ha resultado del contacto ha generado formas cartageneras de cultura popular. En ese sentido, lo popular cartagenero resulta, en cierta forma, una forma más allá de lo nacional, una mezcla refinada de múltiples tiempos y lugares identitarios. 
Surge, también, una realidad social "otra" que constituye la segunda parte (las parte más rica e interesante) de la bifurcación popular. Bebiendo de este espacio privilegiado de síntesis turística existe, en el mapa de las dinámicas sociales de la ciudad, un tercer espacio hibrido que se posiciona simbólicamente como un espacio de marginalidad, pero que surge, en realidad, de la materialidad de las dinámicas culturales de la Cartagena internacional de las últimas décadas. Tal género es, sin duda, la Champeta, la cual ha venido transformando, lenta pero paulatinamente, la comunidad sónica del Caribe colombiano y la identidad misma de la cartegeneidad ${ }^{15}$.

Carlos Vives ha sido, quizá, quien mejor ha consignado el impacto "champetúo" en el imaginario cultural más allá de la ciudad y la región. Su canción Cartagena la fantástica (2013) habla de un desplazamiento en el horizonte de referencias culturales que rebate, a todas luces, el imaginario hispánico de finales de siglo $\mathrm{XX}$. Es curioso que Vives, galán, músico y productor, hijo de las élites locales, libere, con esta champeta, una memoria histórica traumada, que encuentra mejor desahogo a través de una música y un baile que muchos le endilgarían como ajeno. Bien pensado, fantástico termina siendo un adjetivo que alude, en realidad, a una herida todavía sin sanar que Vives (y muchos más) entiende como parte constitutiva de una injusticia histórica. Las viejas murallas dan paso, en la imagen de ciudad construida por el artista, a las gentes humildes que nunca han disfrutado de Cartagena porque nunca han podido sentirla suya. Los vendedores, las empleadas domésticas, los desempleados e indigentes que no aparecen en los folletos promocionales se convierten, por fin, en ciudadanos cartageneros:
Manuel Zapata me dijo
Domingo benkos biohó
Se libertó en Cartagena
Y en la Matuna fundó
Palenque
Para escapar de su suerte
Para llamar a su gente
Para cantar por sus penas
Me lo contó
Dios bendiga Cartagena
La fantástica
Viva el África ${ }^{16}$

15 Edinson Cueto Quintero, $<<$ La Música Champeta: un movimiento de resistencia cultural afrodescendiente a través del cuerpo>>, Daimon Revista Internacional De Filosofia 5 (2016), 651-8.

16 Cartagena la fantástica," Youtube, Filmaciones Cartagena, diciembre 17, 2013, https://www.youtube.com/ watch?v=7kejSqsKuvE 


\section{Segunda voz del contrapunto: transitando hacia Cartagena "la fantástica"}

\subsection{Acuerdos en torno a la "Champetuidad"}

Hablar de la canción permite abordar aspectos relativos a la representación social. Se puede partir de un hecho innegable: aunque a muchos les disguste, Cartagena de Indias ha sido, desde el inicio, un pueblo caribeño agrupado dentro de un marco cultural principalmente atlántico-diaspórico. Existe, por supuesto, una transversalidad intrínseca a ese posicionamiento identitario, el cual se expresa en la africanidad básica de la música autóctona. Pero por más paradójico que resulte para los puristas aceptarlo, esta condición, lejos de atenuarse, se refuerza muchísimo más con el creciente cosmopolitismo que el auge turístico impulsa en la ciudad. Con la llegada de formas foráneas, se consolida una idea de negritud cartagenera que no hubiese encontrado por sí sola la fuerza necesaria para consolidarse. Esto, por supuesto, no se da por arte de magia. Aunque el proceso data de décadas, con la llegada previa de la música cubana y puertorriqueña, en realidad, el hito definitivo en la consolidación de lo que hoy se reconoce como lo popular cartagenero se da en los ' 80 , cuando se realiza en la ciudad la primera versión del Festival de Música del Caribe.

Se intensifica, con este festival, la llegada a la ciudad de ritmos procedentes de diferentes regiones de África y las Antillas, que marcan el principio de la cultura "champetúa" y su expresión definitiva, el pick up. Paralelas a esta explosión de afrocaribeñidad, empiezan a aparecer las nuevas modas y costumbres. A caballo de los trenzados a la rasta, los tenis de goma blanca y la ropa "fluor", la parafernalia ochentera se instala en el mundo popular junto con las primeras piezas del cantante palenquero Viviano Torres ${ }^{17}$. En los muelles, las plazas y las calles aparecen palabras nuevas, vocablos que le dan vida nueva al idioma local, y que luego, re-semantizados, relatan las historias de una urbe que se extiende más allá de los límites que se ha impuesto a sí misma. Esa es la "Champeta", una reapropiación del término que originalmente se refiere al cuchillo grande con que los pescadores del mercado público destripan su producto, y que a partir de ese momento nombrará una forma de escuchar y bailar propia de los mercaderes, pescadores y vendedores ambulantes que constituyen las mayorías cartageneras ${ }^{18}$.

\subsection{Problemas y desafíos de lo "Champetúo"}

Mientras crece la champeta, crece la ciudad y los problemas urbanos. La expansión de la zona turística implica el desplazamiento de barrios enteros. La Cartagena turística crea, en su empuje, a la otra Cartagena, no solo en su ritmo, sino

17 Para ver más sobre cultura champetúa ir a "Champetúa documental”. Youtube, La lupa, periódico, https:// www.youtube.com/watch?v=auV60NGim3U

18 Cueto Quintero, "La Música Champeta: un movimiento de resistencia". 
en su materialidad misma. En medio de una situación tan caótica, la champeta se transforma en un ritmo de vida que intenta encontrar una solución. Por esa razón, su potencial político reside en el modo concreto en que desestabiliza las convenciones de subjetividad, raza, corporalidad y ciudadanía en una ciudad segregada.

De allí la necesidad de entender como la fantástica construye un espacio subversivo donde acontecen pequeñas revoluciones cotidianas. Político en su apoliticidad, el género tiene un carácter subversivo que sus detractores sienten con una fuerza que aquellos que la gozan y defienden a menudo no alcanzan a dimensionar totalmente. Si esto se debe a sus conexiones con las formas populares de amar, comer, gozar y danzar ies vivir como si se bailara champeta el camino a una ciudadanía opuesta al desencanto y una crisis que parece eterna? Si el goce "champetúo" puede articular resistencia, sobre todo en un lugar donde la mayoría subsiste en la miseria, puede profundizarse todavía más en la particularidad de sus revueltas.

\section{¿Conclusiones o puntos de partida?: armonías y desbalances del contrapunto cartagenero}

Para considerar el rejuego material y simbólico que existe entre las supuestamente inconexas realidades de Cartagena, existen por lo menos dos intersecciones que vale la pena mencionar:

La primera de estas intersecciones consiste en un modo de entender las dinámicas sociales de la ciudad no como ejercicios culturales sino como ejercicios interculturales. Mas allá del ensalzamiento de lo negro popular por lo negro popular, promover el entendimiento de la historia local desde la relación y no desde la separación, es decir, a través del dialogo entre identidades interdependientes, desestructura el falso progresismo existente en el lamentable cúmulo de lecturas pesimistas del poder y la agenda social desde el cual la realidad local es interpretada. Se supera así la práctica académica "del pobre negro" para poner de relieve la capacidad de la cultura cartagenera para no cerrarse en sí misma, para erigirse en un núcleo creativo capaz de proponer respuestas novedosas y necesarias, un espacio de autoafirmación en el cual los sujetos subordinados navegan con audacia las encrucijadas de una situación difícil. Pensar el soundscape cartagenero como la subversión de la exclusión permite comprender que los temas, los motivos y, las imágenes que fundan su imaginario no son tan fácilmente divisibles como a menudo se pretende.

No obstante, aunque la idea de "las dos Cartagenas" (una negra y una blanca, una rica y una pobre) se muestre sin fundamento, la experiencia objetiva y subjetiva de la segregación sigue siendo completamente real. Esto obliga a añadir matices a la forma de entender la realidad de la ciudad: admitir la existencia de un mundo popular subordinado y subvalorado es inexorable; falsear la cuestión diciendo 
que este mundo es un mundo dominado, excluido, derrotado y sin esperanza... jamás. Puesto que la lucha del ciudadano de a pie es por una mayor integración, el espacio urbano es, en todo momento, un ámbito de resistencia que existe precisamente a través del contacto.

Pero nada de esto tiene sentido si no se le añade una mirada hacia adentro. Es conveniente recordar que la labor intelectual se liga con la realidad con tanta fuerza como se liga al aparato disciplinar que regula la academia como espacio ideológico-discursivo, sociopolítico y simbólico. De cara a la mentalidad de balcanización y descontextualización que exhiben muchas modas intelectuales actuales, la investigación debe plantearse dinámicas epistémicas y epistemológicas más enfocadas en la autorreflexión sobre el método. Mas aun, los investigadores de la cultura del Caribe colombiano necesitan seguir buscando su propio camino, uno marcado por el indispensable equilibro entre el desarrollo conceptual y la transformación del rol del investigador en las dinámicas de poder, pues tal como sucede con la cultura de la exclusión, una academia que importa ciegamente también funciona como espacio político de opresión. Construir una academia de diálogo, que abandone la jerarquización vertical de realidades que no siempre comprende bien, solamente es posible al considerar, como si fuesen las dos caras de una misma moneda, la oscilación entre la interconexión y el distanciamiento.

Esto conduce a la segunda intersección, la cual implica reconsiderar la manera en que entendemos la identidad. Al igual que la cultura, la identidad se mueve de modo heterogéneo y esto se observa en las dinámicas de construcción identitarias en donde los cruces, las hibridaciones, los intercambios y las violencias están a la orden del día. Siendo esto tan evidente, no se explica bien el porqué se tiende a olvidar que la identidad debe entenderse como conflictiva, estratégica y posicional, lo cual equivale a decir, palabras más, palabras menos, que nunca es posible entenderla en singular sino en plural, una pluralidad que arrastra consigo, para bien y para mal, posibilidades misceláneas y contradictorias.

Esto significa que cuando se debate sobre las narrativas sociales mediante las cuales las identidades se construyen, hay que recordar el simple e innegable hecho de que la consolidación de estas identidades depende de ese elemento tan importante que es el otro. Aunque la identidad es también un proceso de exclusión de cosas que no parecen encajar en la formación de un sujeto o grupo, lo que en apariencia queda por fuera es realmente esencial. Es solamente en el reconocimiento y la aceptación de lo exterior en donde radica un auténtico entendimiento de la identidad $^{19}$. En ese sentido, el caso cartagenero ofrece una valiosa verdad, tal es, la otredad es crucial para entender las oposiciones y los descentramientos que

19 Edouard Glissant, The Poetics of Relation (Ann Arbor: University of Michigan Press, 1997). 
se dan dentro de los sujetos y las visiones de mundo que ordenan la realidad. La música (el universo de lo popular) en Cartagena no separa, sino que, al contrario, constituye una forma de apertura que da voz a los acallamientos, que brinda presencia, en la gran vitrina social, a las masas que no se han dejado arrinconar por el espejismo distante del progreso. Al subvertir lúdicamente una tradición excluyente, darle salida al descontento e intentar, de paso, llegar a una solución, la Cartagena de las mayorías demuestra que no se amilana ante las promesas incumplidas por los proyectos políticos modernos.

\section{Bibliografía}

Alberto Abello Vives. <<Introducción >>. En Los desterrados del paraíso. Raza, pobreza y cultura en Cartagena de Indias, 6-9. Edición de Alberto Avello Vives y Francisco Flórez Bolívar. Cartagena: Instituto de Cultura y Turismo de Bolívar / Icultur /Gobernación de Bolívar, 2015.

Bhabba, Homi. El lugar de la cultura. Argentina: Estudio R cultura libre, 1994.

Caro, Isela. $<<$ Cartagena: ciudad monumental para el turismo y discurso glorificador en la prensa local de mediados del siglo $\mathrm{XX}>>$. En Visitas al patio 5 (2011): 67-84.

Carpentier, Alejo. La música en Cuba. México: Siglo XXI editores, 1987.

Chajín Mendoza, Osiris María. <<"Los poetas de sus asuntos": migraciones, rupturas y reconfiguraciones de las culturas juveniles en Cartagena $>>$. En Cuadernos de Literatura 7 (2008). Accedido septiembre 19, 2021. http://investigaciones.uniatlantico.edu.co/revistas/index.php/cuadernos_literatura/ article/view/489.

Cueto Quintero, Edinson. $<<$ La Música Champeta: un movimiento de resistencia cultural afrodescendiente a través del cuerpo $>>$. En Daimon Revista Internacional De Filosofia 5 (2016): 651-658. https://doi.org/10.6018/ daimon/270971.

Dávila Pertuz, Orlando. $<<$ Construyendo sospechas: imaginarios del miedo, segregación urbana y exclusión social en Cartagena 1956-1971>>. En Cuadernos de Literatura del Caribe e Hispanoamérica 7 (2008): 1-12. http://investigaciones.uniatlantico.edu.co/revistas/index.php/cuadernos_literatura/ article/view/477

Glissant, Édouard. The Poetics of Relation. Ann Arbor: University of Michigan Press, 1997. 
Hall, Stuart. $<<$ Estudios Culturales: dos paradigmas $>>$. En Sin garantías. Trayectorias y problemáticas en Estudios Culturales, 29-51. Edición de Eduardo Restrepo, Catherine Walsh y Víctor Vich. Ecuador: Corporación Editora Nacional/Universidad Andina Simón Bolívar, 2013.

Hall, Stuart. $<<$ Qué es lo "negro" en la cultura popular negra?>> En Sin garantías. Trayectorias y problemáticas en Estudios Culturales. Edición de Eduardo Restrepo, Catherine Walsh y Víctor Vich. Ecuador: Corporación Editora Nacional/Universidad Andina Simón Bolívar, 2013.

Instituto de Crédito Territorial. Chambacú: Regeneración de una zona de tugurios. Cartagena: ICT, 1956.

Instituto de Crédito Territorial. Zona Negra. Cartagena: ICT, 1955.

Lacarrieu, Mónica. $<<$ La insoportable levedad, de lo urbano $>>$. Eure-revista Latinoamericana De Estudios Urbano Regionales - EURE 33 (2007): 47-64.

Miller, Shawn William. An Environmental History of Latin America. Cambridge: Cambridge University press, 2007.

Miranda, Ricardo, Tello, Aurelio. La música en Latinoamérica. México: Secretaría de relaciones exteriores, 2011.

Mosquera Rosero-Labbé, Claudia, Provansal, Marion. $<<$ Construcción de identidad caribeña popular en Cartagena de Indias por medio de la música y el baile de champeta>>. En Los desterrados del paraíso. Raza, pobreza y cultura en Cartagena de Indias, 422-448. Edición de Alberto Avello Vives y Francisco Flórez Bolívar. Cartagena: Instituto de Cultura y Turismo de Bolívar / Icultur /Gobernación de Bolívar, 2015.

Niño, Soledad, Nelson Lugo Torres, Cesar Rozo, Leonardo Vega. Territorios del miedo: imaginarios de los ciudadanos. Bogotá: TM Editores - Observatorio de Cultura Urbana, 1998.

Veal, Michael. $<<$ Starship Africa $>>$. En The Sound Studies Reader. Edición de Jonathan Stern. Londres: Routledge, 2012. 
